TITLE:

\title{
Application of nanoparticles dispersed polymer to micropowder blasting mask
}

$\operatorname{AUTHOR}(\mathrm{S})$ :

Yagyu, H; Hayashi, S; Tabata, O

\section{CITATION:}

Yagyu, H ...[et al]. Application of nanoparticles dispersed polymer to micropowder blasting mask. JOURNAL OF MICROELECTROMECHANICAL SYSTEMS 2004, 13(1): 1-6

\section{ISSUE DATE:}

2004-02

URL:

http://hdl.handle.net/2433/50193

\section{RIGHT:}

(c)2004 IEEE. Personal use of this material is permitted. However, permission to reprint/republish this material for advertising or promotional purposes or for creating new collective works for resale or redistribution to servers or lists, or to reuse any copyrighted component of this work in other works must be obtained from the IEEE. 


\title{
Application of Nanoparticles Dispersed Polymer to Micropowder Blasting Mask
}

\author{
Hiromasa Yagyu, Member, IEEE, Shigehiko Hayashi, and Osamu Tabata, Senior Member, IEEE
}

\begin{abstract}
Improvements in micropowder blasting have been realized for rapid prototyping of channels in glass substrates. The technique presented in this study consists of laser patterning of Au nanoparticles dispersed polymer and micropowder blasting. The patterned polymer was utilized as a mask material for the subsequent mechanical removal of the glass by the micropowder blasting. Five different polymers were tested for the matrix material. Using a line and space mask pattern of $110 \mu \mathrm{m}$ in width, fabricated channels were created in the glass with a maximum aspect ratio of 2.1. The validity of the micropowder blasting using Au nanoparticles dispersed polymer mask was confirmed; additionally, we demonstrated that the micropowder blasting technique with elevated polymer mask temperature was able to reduce erosion of the polymer mask.

[1081]
\end{abstract}

Index Terms-Laser machining, nanoparticle, polymer mask, powder blast.

\section{INTRODUCTION}

$\mathbf{P}$ OWDER blasting with microparticles (micropowder blasting) is a very promising technique for microfabrication in brittle materials such as glass, ceramics and silicon. This technique is faster and cheaper than other microfabrication processes and has been widely used in applications such as electrical device marking, flat panel display production, etc., [1]. These features make micropowder blasting using a patterned mask an attractive option in the field of microelectromechanical systems (MEMS) microfabrication [2]-[4]. We have developed a microfabrication technique that combines micropowder blasting with a mask having high erosion resistance, for use in high aspect ratio machining of brittle materials. In addition, a dry film [5] of negative resist based on polyurethane and electroplated metal masks [6] has also been used as a micropowder blasting mask. There has been a strong demand for a rapid prototyping technique for glass substrates for a micro total analysis system ( $\mu \mathrm{TAS})$. However, the methods described to date have always included a photolithography step, making them unsuitable for this purpose because the processing time is longer and processing costs are higher. If a mask material with high resistance to erosion and high aspect ratio patterning ability can be pattered without photolithography, it will be a very powerful and promising technique for the prototyping of $\mu$ TAS with micropowder blasting.

Manuscript received June 26, 2003; revised September 25, 2003. Subject Editor G. B. Hocker.

H. Yagyu and S. Hayashi are with the Mitsuboshi Belting Ltd., Kobe 6530024, Japan (e-mail: h-yagyu@mitsuboshi.co.jp).

O. Tabata is with the Department of Mechanical Engineering, Kyoto University, Kyoto 606-8501, Japan.

Digital Object Identifier 10.1109/JMEMS.2003.823217

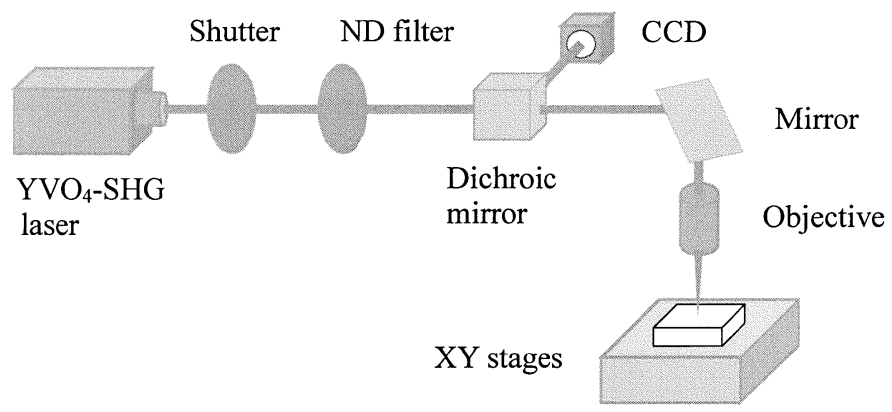

Fig. 1. Schematic diagram of laser microfabrication system.

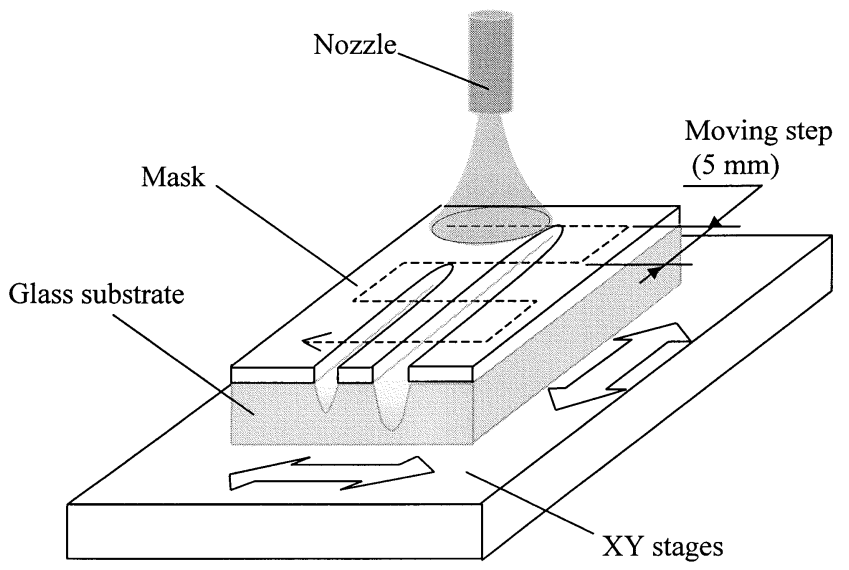

Fig. 2. Schematic diagram of the micropowder blasting process.

TABLE I

THE CONDITION OF THE POWder BLasting

\begin{tabular}{ll}
\hline Material of the particle & $\mathrm{SiC}(\mathrm{GC} \# 600)$ \\
Particle mean diameter & $20 \mu \mathrm{m}$ \\
Blasted pressure & $0.30 \mathrm{MPa}$ \\
Distance from the sample & $100 \mathrm{~mm}$ \\
Amount of blasted & $160 \mathrm{~g} / \mathrm{min}$ \\
Nozzle diameter & $8 \mathrm{~mm}$ \\
Stage moving speed & $50 \mathrm{~mm} / \mathrm{s}$ \\
Stage moving step & $5 \mathrm{~mm}$ \\
\hline
\end{tabular}

We have developed a new polymer resist in which $\mathrm{Au}$ nanoparticles with a mean diameter of $3.4 \mathrm{~nm}$ are densely dispersed. Since this resist shows strong absorption in the visible wavelength region (about $530 \mathrm{~nm}$ ), it can be processed using a focused $\mathrm{Nd}$ : $\mathrm{YVO}_{4}-\mathrm{SHG}$ laser beam $(\mathrm{CW}$, wavelength 
TABLE II

Mechanical Properties of the Polymer Mask Material

\begin{tabular}{ccccccc}
\hline No. & AuPU1 & AuPU2 & AuPU3 & AuPU4 & AuEC & BF405 \\
\hline Matrix polymer & Acryl-PU & Acryl-PU & PET-PU & PET-PU & EC & (Acryl-PU) \\
& Ureol 600 & $49-394-I M$ & D7-880 & D7-885 & & (A) \\
\hline Au concentration [wt\%] & 17 & 17 & 17 & 17 & 17 & - \\
\hline Hardness [HS] & 54 & 73 & 64 & 73 & 96 & 71 \\
Tensile strength [MPa] & 6.9 & 5.7 & 3 & 3.1 & 57.5 & 176 \\
Tensile elongation [\%] & 217 & 60 & 80 & 44 & 50 & 200 \\
Modulus 100\% [MPa] & 2.7 & - & - & - & - & 128 \\
\hline Peak temperature of $E^{\prime}\left[{ }^{\circ} \mathrm{C}\right]$ & 0.6 & 1.2 & -20.2 & -29.9 & 123.6 & -25.0 \\
Peak temperature of $E^{\prime \prime}\left[{ }^{\circ} \mathrm{C}\right]$ & 1.0 & 5.9 & -16.1 & -26.0 & 125.6 & -23.1 \\
Peak temperature of $\operatorname{Tan} \delta\left(E^{\prime \prime} / E^{\prime}\right)\left[{ }^{\circ} \mathrm{C}\right]$ & 42.5 & 34.4 & 6.2 & -10.9 & 138.1 & 0.3 \\
\hline
\end{tabular}

PET-PU: polyester-Polyurethane, Acryl-PU: Acryl-Polyurethane, EC: Ethylcellulose

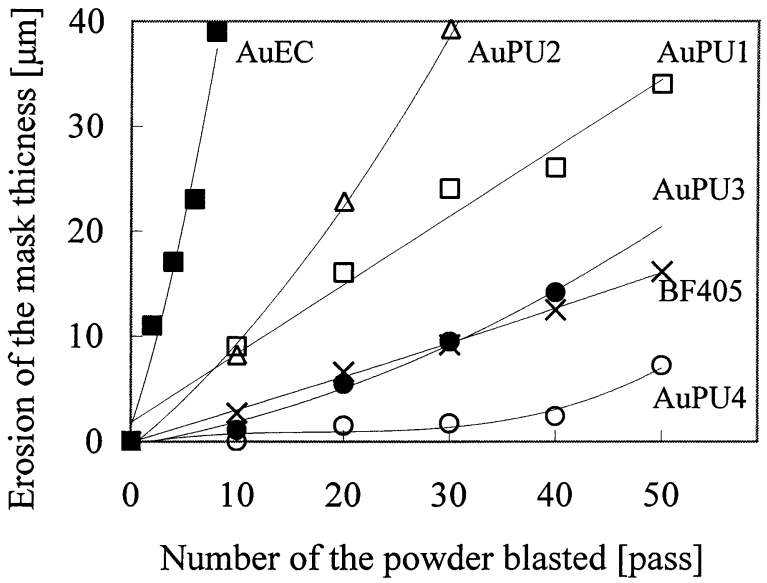

Fig. 3. Dependency of the mask thickness erosion on the number of the powder blasting passes using $\mathrm{SiC}$ microparticles (mean diameter of $20 \mu \mathrm{m}$ ).

of $532 \mathrm{~nm}$, output power below $30 \mathrm{~mW}$ ) [7]. One of the benefits of this fabrication technique is that a microscale channel and hole with high aspect ratio can be fabricated using a low power output laser without the need for a photolithography step.

In this paper, we report on the results of mechanical property measurements on the polymer mask, the erosion resistance of Au nanoparticles dispersed in the polymer mask by micropowder blasting, and the fabrication of glass substrate with this polymer mask.

\section{EXPERIMENTAL PROCEDURES}

\section{A. Mask Materials}

Five different polymers were used for matrix material: two polyester polyurethane (Burnock D7-880, D7-885, Dainippon Ink \& Chemicals, Inc., Tokyo, Japan), two acryl polyurethane (Ureol 600, Kawakami Print, Co., Ltd., Hyogo, Japan; Acrydic 49-394-IM, Dainippon Ink \& Chemicals, Inc., Tokyo, Japan) and ethylcellulose (Wako Pure Chemical Industries, Ltd., Osaka, Japan). Au nanoparticles with mean diameter of 3.4 nm (Perfect Gold, Vacuum Metallurgical Co., Ltd., Tokyo, Japan) produced by gas evaporation technique were used for nanoparticles. Au nanoparticles dispersed polyurethane

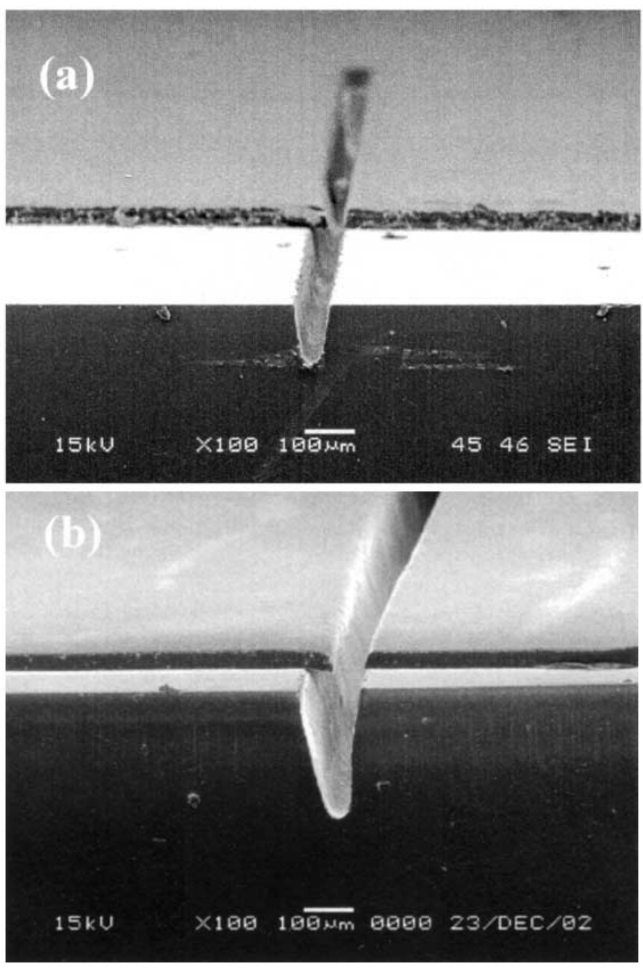

Fig. 4. SEM images of the fabricated channel using Au nanoparticles dispersed polyurethane (AuPU4) mask and $20 \mu \mathrm{m}$ microparticle. The line opening width of the mask was $60 \mu \mathrm{m}$ (a) and $110 \mu \mathrm{m}$ (b). The number of the powder blasting was 30 passes.

(AuPU1-AuPU4) paste and ethylcellulose (AuEC) paste with an $\mathrm{Au}$ concentration of $17 \mathrm{wt} \%$ in the solid were prepared by mixing the polymer dissolved in the solvent with Au nanoparticles. In addition, a general powder blasting mask (Ordyl BF405, Tokyo Ohka Kogyo Co., Ltd., Tokyo, Japan) was tested as a reference mask material. BF405 is an elastic negative resist film with a thickness of $50 \mu \mathrm{m}$.

The mechanical properties (hardness, tensile strength, tensile elongation, modulus, dynamic viscoelasticity) of all materials were measured together with the erosion resistance for micropowder blasting. The dynamic viscoelasticity, the peak temperatures for the storage modulus $\left(E^{\prime}\right)$, loss modulus $\left(E^{\prime \prime}\right)$ and loss 


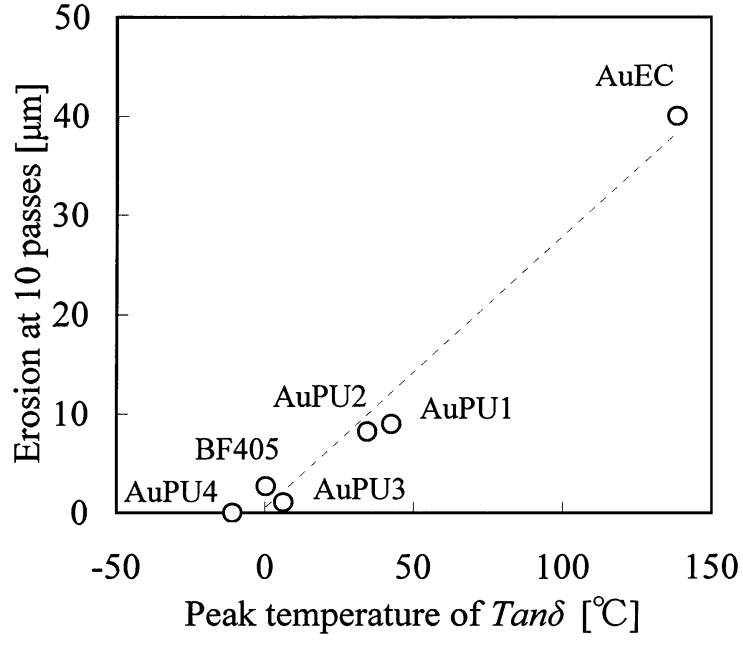

Fig. 5. Relationship between erosion by 10 passes of micropowder blasting and the peak temperature of $\operatorname{Tan} \delta$

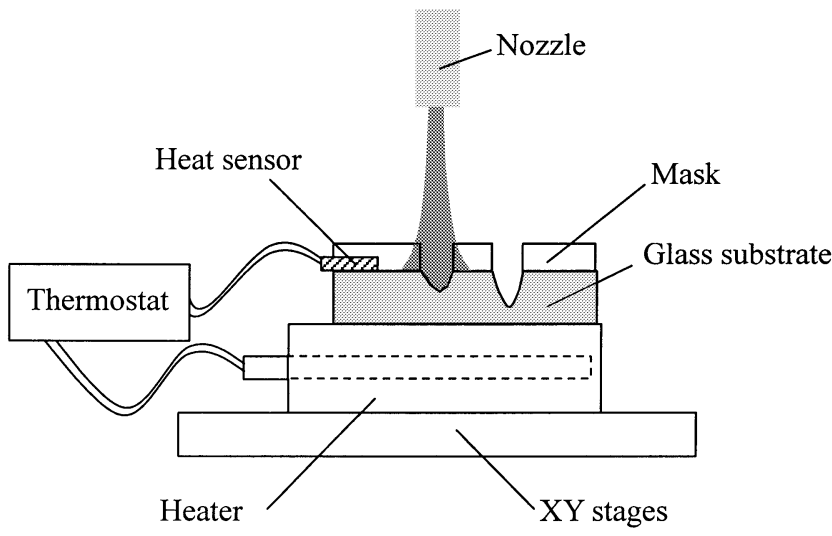

Fig. 6. Configuration of micropowder blasting system for controlling the mask temperature.

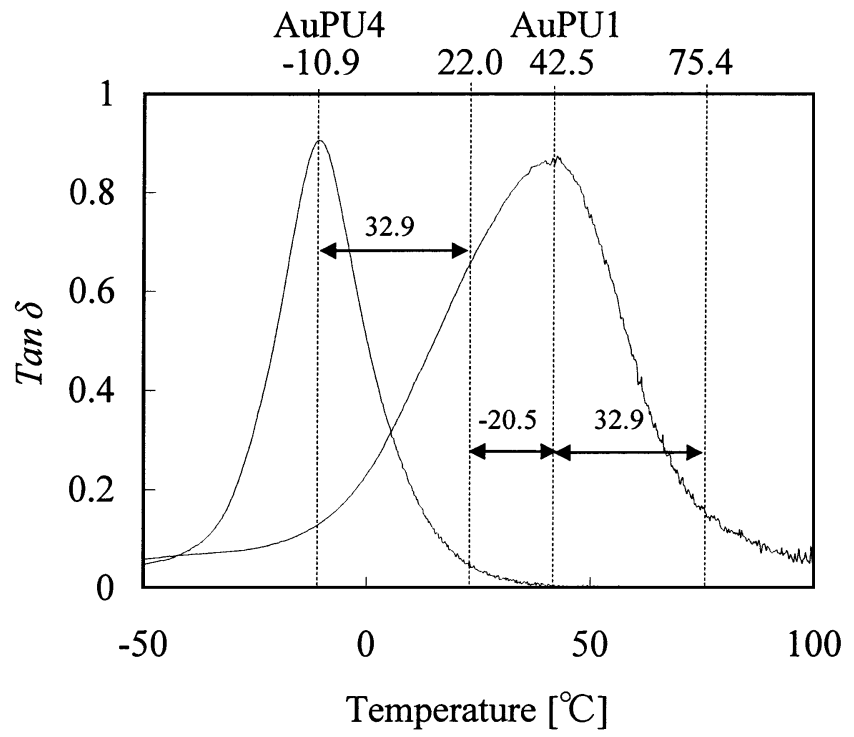

Fig. 7. Dependency of loss tangent $\left(\operatorname{Tan} \delta=E^{\prime \prime} / E^{\prime}\right)$ of AuPU1 and AuPU4 on the temperature.

tangent $\left(\operatorname{Tan} \delta=E^{\prime \prime} / E^{\prime}\right)$ were measured by Dynamic Mechanical Analysis (DMA). Sheets with a thickness of $2 \mathrm{~mm}$ were

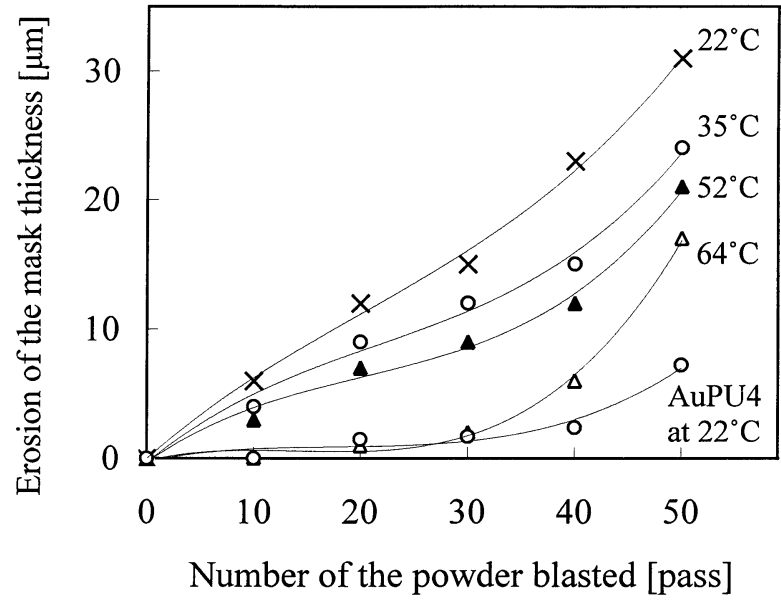

Fig. 8. Dependency of AuPU1 mask thickness erosion on the number of powder blasting passes. The temperature of the mask was $22,35,52$ and $64^{\circ} \mathrm{C}$.

prepared using molding techniques in order to measure the mechanical properties of all polymer masks. For measurement of the erosion along the thickness direction, another sample was prepared by coating a glass substrate with $30 \mu \mathrm{m}$ of paste using an applicator, and baking at $80^{\circ} \mathrm{C}$ for $30 \mathrm{~min}$. As pinholes in the mask will cause detects in the glass substrate after powder blasting, coating was carefully operated to minimize these pinholes. In the case of using thinner resist than $30 \mu \mathrm{m}$, a lateral erosion rate of the mask was high and the processed channel in a glass had a lower aspect ratio. On the other hand, for the thicker resist, the channel with high aspect ratio cannot be also fabricated in the glass, because the mask pattern with a large depth cannot be processed by laser beam, or particle for powder blasting was accumulated in opening of the mask pattern. These samples were also utilized for the machining of the glass using the patterned paste as a mask for the micropowder blasting. A powder blasting system (Microblaster MB1, Shinto Brator Co., Ltd., Nagoya, Japan) using a silicon carbide (SiC) microparticle with a mean diameter of $20 \mu \mathrm{m}$ was utilized in this study.

\section{B. Laser Processing}

Fig. 1 shows the configuration of the laser microfabrication system using an $\mathrm{Nd}: \mathrm{YVO}_{4}$-SHG laser (58GC42, CW, wavelength of $532 \mathrm{~nm}$, Melles Griot, Inc., Carlsbad, CA, USA) which has a wavelength near the plasmon resonance absorption peak for Au nanoparticles. The system is small and low-cost since the output power of the laser is $23 \mathrm{~mW}$ and the cooling laser device is unnecessary.

The laser beam was focused on a polymer mask with an objective lens with a magnification of 10 and a numerical aperture of 0.25 . The patterns were directly drawn on the polymer mask by controlling the laser beam position with programmable moving XY stages. The intensity of the irradiated laser beam was adjusted within the range from 1 to $23 \mathrm{~mW}$ using an ND filter. The movement speed of the XY stages was set at $0.5 \mathrm{~mm} / \mathrm{s}$. The calculated diameter $d$ of the focused laser beam was $10 \mu \mathrm{m}$ and the incident angle $2 \theta$ was $6 \times 10^{-4} \mathrm{rad}$. In this study, mask patterns of width 60 and $110 \mu \mathrm{m}$ in width were fabricated by moving the XY stages in steps of $2.5 \mu \mathrm{m}$, since the diameter of the focused laser beam spot was small in comparison with the required line width. In the case of writing the line pattern 
of $100 \mu \mathrm{m}$ in width and $10 \mathrm{~mm}$ in length using this laser processing condition, it took about $13 \mathrm{~min}(20 \mathrm{~s} * 40 \mathrm{step}=800 \mathrm{~s}$ $=13.3 \mathrm{~min}$ ) to complete the mask pattern. From our previous study [7], we have confirmed the processed depth and width depend on laser processing condition and Au concentration of the mask. Hence, this processing time can be shorten by a faster movement speed with higher intensity of irradiated laser beam and a higher Au concentration mask.

\section{Micropowder Blasting}

Table I shows the conditions under which micropowder blasting was carried out. The $\mathrm{SiC}$ microparticles with a mean diameter of $20 \mu \mathrm{m}$ were accelerated from the nozzle (diameter of $8 \mathrm{~mm}$ ) toward the sample with high-pressure airflow and an incident angle of $90^{\circ}$. In order to process the entire surface of the glass substrate, the substrate was scanned repeatedly hereafter each scanning session is referred to as a "pass" by the XY stages with the constant velocity and a moving step shown in Fig. 2. When the glass substrate coated with the patterned polymer mask was hit by the $\mathrm{SiC}$ microparticles, it was machined in the open areas of the polymer mask due to the difference in the erosion rate between the polymer mask and the exposed glass substrate. The processed glass was immersed in water to remove the mask after powder blasting. We didn't clean a processed glass substrate in this work, because microparticles and mask debris were not observed in the channel. In order to clarify the dependency of polymer mask erosion along the thickness on the number of passes, the thickness of the mask was measured with a profile meter (Alpha- Step 500, KLA-Tencor Co., San Jose, CA) after the powder blasting. The fabricated channels in the glass substrate were observed using the patterned polymer mask with scanning electron microscopy (SEM).

\section{RESUlT AND DISCUSSION}

\section{A. Mechanical Properties of the Polymer Mask Material}

Table II shows the mechanical properties of the polymer mask material. BF405 showed a comparatively high tensile strength and tensile elongation, and a low peak temperature of $\operatorname{Tan} \delta$. The peak temperatures of $E^{\prime}, E^{\prime \prime}$ and $\operatorname{Tan} \delta$ were highest for AuEC, and lowest for AuPU4.

\section{B. The Erosion of the Mask}

Fig. 3 shows the dependency of the erosion of mask thickness on the number of passes. AuPU4 (polyester polyurethane) showed the best erosion resistance and its erosion value was 0.4 times lower than that of BF405 at 50 passes.

\section{Machining of Glass Substrate}

Utilizing the sample coated with AuPU4, which showed the highest erosion resistance, line patterns of width 60 and $110 \mu \mathrm{m}$ in width were patterned with an irradiated laser beam power of $23 \mathrm{~mW}$, followed by the machining of glass substrate by 30 passes of powder blasting. The channel fabricated on the glass substrate had an aspect ratio (depth/width) of 1.7 (for a width of $60 \mu \mathrm{m}$ ) and 2.1 (for a width of $110 \mu \mathrm{m}$ ) as shown in Fig. 4. In the case of processing of a glass substrate using line pattern of
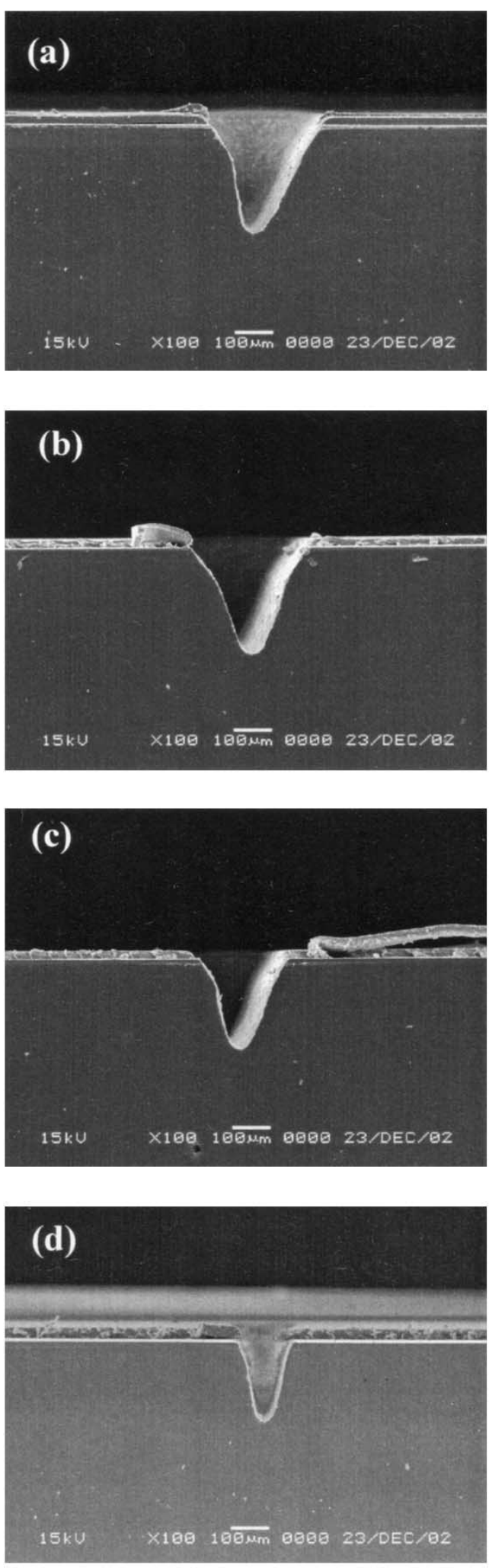

Fig. 9. Cross sections of the fabricated channel on the glass substrate using AuPU1 mask with control of the mask temperature (a) $22{ }^{\circ} \mathrm{C}$, (b) $35^{\circ} \mathrm{C}$, (c) $52{ }^{\circ} \mathrm{C}$, and (d) $64{ }^{\circ} \mathrm{C}$, respectively. Line width of the mask was $60 \mu \mathrm{m}$.

$110 \mu \mathrm{m}$ in width, the processed channels depth and aspect ratio in the glass ranged in variation from $161 \mu \mathrm{m}$ to $246 \mu \mathrm{m}$, and from 1.6 to 2.1 , respectively. This variation will be reduced by optimization of powder blasting condition (particle size, blasted 


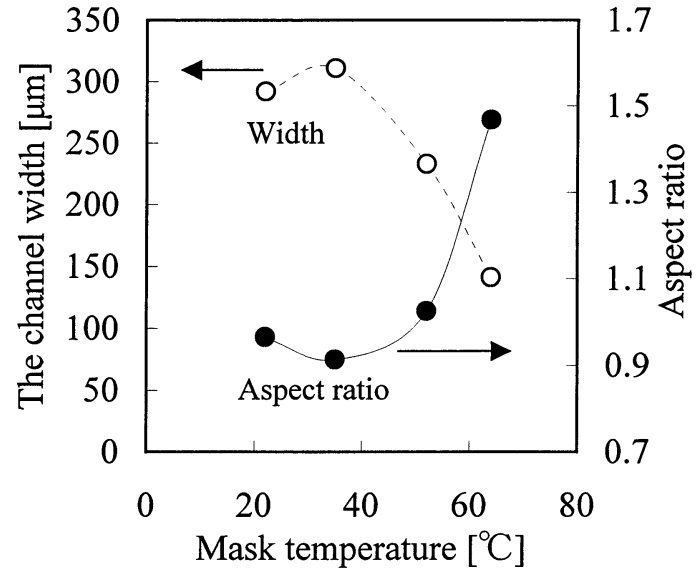

Fig. 10. Relationship between the channel width and aspect ratio of the fabricated channel on the glass substrate and the mask temperature. The line width of the mask was $60 \mu \mathrm{m}$.

pressure and so on). These results confirm the validity of the micropower blasting technique using Au nanoparticles dispersed polyurethane.

\section{Temperature Control of the Polymer Mask}

Careful observation of the relationship between erosion resistance by micropowder blasting and the mechanical properties of the polymer mask materials revealed that the erosion of the polymer mask material strongly depended on dynamic viscoelasticity, specifically, on the peak temperature of Tan $\delta$. Fig. 5 shows the relationship between erosion by 10 passes of micropowder blasting and the peak temperature of $\operatorname{Tan} \delta$. The erosion decreased in proportion to the decrease in peak temperature of $\operatorname{Tan} \delta$ for the polymer mask material. Hutchings et al. studied the relationship between the erosion resistance of an elastomer by particle impact and the its mechanical properties, concluding that erosion increases with a decrease in rebound resilience [8]. Since rebound resilience, which involves the absorbed energy in an elastomer, shows a minimum at the peak temperature of $\operatorname{Tan} \delta$, it is expected that erosion resistance will improve when the temperature difference between the peak temperature of $\operatorname{Tan} \delta\left(T_{1}\right)$ and the processing polymer mask temperature $\left(T_{2}\right)$ is increased $\left(\Delta T=T_{2}-T_{1}\right)$.

In order to confirm this speculation, powder blasting was conducted while controlling the temperature of AuPU1 mask. Since the $\operatorname{Tan} \delta$ peak temperature of AuPU1 is $42.5^{\circ} \mathrm{C}$, which is above room temperature, it is possible to increase $\Delta T$ for AuPU1 by heating the mask material. Fig. 6 shows the configuration for this experiment. The temperature of the polymer mask was controlled at a constant value with a thermostat and the heat sensor was inserted between the glass substrate and the polymer mask.

The AuPU4 has a $\Delta T$ of $32.9^{\circ} \mathrm{C}$ as shown in Fig. 7, assuming that the process is carried out at a room temperature of $22^{\circ} \mathrm{C}$. This is the maximum $\Delta T$ among the materials shown in Table II. As both AuPU1 and AuPU4 have same $\Delta T$ of $32.9^{\circ} \mathrm{C}$, we expected to observe comparable erosion resistance if we set the processing temperature of AuPU1 to $75.4^{\circ} \mathrm{C}$. The experiment was carried out with AuPU1 at a temperature of $64{ }^{\circ} \mathrm{C}$ because the possible maximum temperature was limited due to cooling by the airflow blown from the nozzle.
Fig. 8 shows the thickness erosion of the AuPU1 mask as a function of both the number of powder blasting passes (from 0 to 50) and the mask temperature (from 22 to $64^{\circ} \mathrm{C}$ ). The erosion of the AuPU1 mask decreased with increasing temperature, and its erosion values at $64^{\circ} \mathrm{C}$ and 50 passes were 1.1 and 2.4 times lower than those of BF405 and AuPU4 at $22^{\circ} \mathrm{C}$. These results confirm that the erosion resistance of the mask can be improved by increasing the $\Delta T$ of the polymer mask.

The validity of the proposed idea was verified by fabricating microchannels in the glass. The channel profile was determined by measuring the width and depth with SEM. Fig. 9 shows cross-sections of the fabricated channel on the glass substrate using AuPU1 mask and controlling the mask temperature from 22 to $64{ }^{\circ} \mathrm{C}$. As anticipated, the fabricated channel width and aspect ratio showed a strong dependency on the mask temperature, and showed maximum and minimum, respectively, at a mask temperature of $35^{\circ} \mathrm{C}$. The aspect ratio increased with an increase in mask temperature above $35^{\circ} \mathrm{C}$, and showed a decrease of about 1.5 times at a mask temperature of $64^{\circ} \mathrm{C}$, as shown in Fig. 10.

\section{CONCLUSION AND Future WORK}

In the application of Au nanoparticles dispersed polymer for the micropowder blasting mask, it was confirmed that an $\mathrm{Au}$ nanoparticles dispersed polyurethane (AuPU4) mask has a high erosion resistance. A channel with an aspect ratio of 2.1 on the glass substrate was successfully fabricated using an AuPU4 mask.

We also conclude that erosion is strongly correlated with the dynamic viscoelasticity of the mask and that the new technique of performing powder blasting while controlling the mask temperature was successful; the erosion resistance of the polymer mask was improved by this technique.

The laser processing conditions of the polymer mask and the powder blasting conditions will be optimized in future work, and its application of this technique to rapid prototyping of $\mu$ TAS will be examined.

\section{REFERENCES}

[1] H. Fujii, H. Tnabe, M. Harayama, and M. Oka, "A sandblastingprocess for fabrication of color PDP phosphor screens," in Society for Information Display International Symposium Digest 92, 1992, pp. 728-728.

[2] K. Arivi, L. Seppo, and U. Antti, "Rapid prototyping of silicon structures by aid of laser and abrasive-jet machining," Proc. SPIE, vol. 3680, pp. 870-878, 1999.

[3] D. Solignac, A. Sayah, S. Constantin, R. Freitag, and M. A. M. Gijs, "Powder blasting for the realization of microchips for bio-analytic applications," Sens. Actuators, vol. A92, pp. 388-393, 2001.

[4] H. Wensink, H. V. Jansen, J. W. Berenschot, and M. C. Elwenspoek, "Mask materials for powder blasting," J. Micromech. Microeng., vol. 10, pp. 175-180, 2000.

[5] P. J. Slikkerveer, P. C. P. Bouten, and F. C. M. de Haas, "High quality mechanical etching of brittle materials by powder blasting," Sens. Actuators, vol. A85, pp. 296-303, 2000.

[6] H. Wensink, H. V. Jansen, J. W. Berenschot, and M. C. Elwenspoek, "High resolusion powder blast micromachining," in Proc. IEEE Int. Conf. Micro Electro Mechanical Systems, Miyazaki, Japan, Jan. 2000, pp. 769-774.

[7] H. Yagyu, S. Hayashi, and O. Tabata, "Laser microfabrication using nano-particles dispersed polymer resist," in Tech. Dig. Int Conf. SolidState Sensors, Actuators and Microsystems, Boston, MA, Jun. 2003, pp. $762-765$.

[8] I. M. Hutchings and D. W. T. Deuchar, "Erosion of unfilled elastomers by solid particle impact,” J. Mater. Sci., vol. 22, pp. 4071-4076, 1987. 


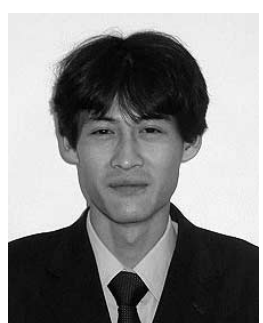

Hiromasa Yagyu (M’02) was born in 1970. He received the B.S. degree in mechanical engineering from Osaka Institute of technology, Osaka, in 1993.

In 1993, he joined Mitsuboshi Belting Ltd., where he worked on function material and its processing technique. He is currently working on metal nanoparticles and microfabrication as a researcher in Ritsumeikan University.

Mr. Yagyu is a Member of the Institute of Electrical Engineers of Japan and the Japan Society for Precision Engineering.

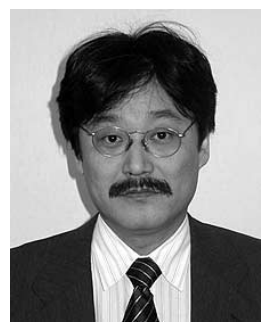

Shigehiko Hayashi was born in 1960 . He received the Ph.D. degree in material science from Kobe University, Kobe, Japan in 1992.

In 1992, he joined Mitsuboshi Belting Ltd., where he has worked on metal nanoparticles.

Dr. Hayashi is a member of Japan Society of Applied Physics and the Optical Society of Japan.

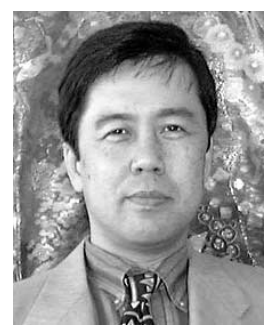

Osamu Tabata (M'89-SM'01) was born in 1956. He received the M.S. and Ph.D. degrees from Nagoya Institute of Technology, Nagoya, Japan, in 1981 and in 1993, respectively.

Since 1981, he has been with the Toyota Central Research and Development Laboratories, Inc., Aichi, Japan. In 1996, he joined the Department of Mechanical Engineering, Ritsumeikan University, Shiga, Japan. From September to December 2000, he was a guest Professor of Institute of Microsystem Technology, Freiburg University, Germany and from January to March 2001, he was a guest Professor of ETH Zurich, Switzerland. In 2003, he joined the Department of Mechanical Engineering, Kyoto University, Kyoto, Japan. He is currently engaged in the research of micro/nano process, LIGA process, MEMS, and micro/nano system synthetic engineering.

Dr. Tabata is an Associate Editor of the JOURNAL OF MicRoeleCtROMECHANICAL SYSTEMS and an Editorial Board member of Sensors and Actuators. He is also a program committee member of many international conferences. He was honored with the Science News Award for research in "Monolithic pressure-flow sensor" in 1987, Presentation Paper Award for research in "Anisotropic etching of silicon in TMAH solutions" in 1992, R\&D 100 Award for research in "Thin film Young's modulus measurement apparatus" in 1993 and R\&D 100 Award for research in "Thin film Tensile Tester" in 1998. He is a Member of the Institute of Electrical Engineers of Japan and the Japan Society of Mechanical Engineers. 